\title{
Insights into the physiological function of cellular prion protein
}

\author{
V.R. M artins ${ }^{1}$, \\ A.F. Mercadante 2,3 , \\ A.L.B. Cabral ${ }^{2,3}$, \\ A.R.O. Freitas ${ }^{2,3}$ and \\ R.M.R.P.S. Castro ${ }^{1}$
}

\author{
${ }^{1}$ Centro de Tratamento e Pesquisa, Hospital do Câncer, \\ IInstituto Ludwig de Pesquisa sobre o Câncer, and \\ ${ }^{3}$ Departamento de Bioquímica, Instituto de Química, \\ Universidade de São Paulo, São Paulo, SP, Brasil
}

\section{Correspondence \\ V.R. Martins \\ Rua Antônio Prudente, 109, 40 andar 01509-010 São Paulo, SP \\ Brasil \\ Presented at \\ SIMEC 2000 - International \\ Symposium on Extracellular \\ Matrix, Angra dos Reis, RJ, \\ Brazil, September 24-27, 2000.}

Publication supported by FAPESP.

Received November 9, 2000 Accepted February 13, 2001

\section{Abstract}

Prions have been extensively studied since they represent a new class of infectious agents in which a protein, PrPsc (prion scrapie), appears to be the sole component of the infectious particle. They are responsible for transmissible spongiform encephalopathies, which affect both humans and animals. The mechanism of disease propagation is well understood and involves the interaction of PrPsc with its cellular isoform $(\mathrm{PrPc})$ and subsequently abnormal structural conversion of the latter. PrPc is a glycoprotein anchored on the cell surface by a glycosylphosphatidylinositol moiety and expressed in most cell types but mainly in neurons. Prion diseases have been associated with the accumulation of the abnormally folded protein and its neurotoxic effects; however, it is not known if PrPc loss of function is an important component. New efforts are addressing this question and trying to characterize the physiological function of PrPc. At least four different mouse strains in which the PrP gene was ablated were generated and the results regarding their phenotype are controversial. Localization of PrPc on the cell membrane makes it a potential candidate for a ligand uptake, cell adhesion and recognition molecule or a membrane signaling molecule. Recent data have shown a potential role for PrPc in the metabolism of copper and moreover that this metal stimulates PrPc endocytosis. Our group has recently demonstrated that PrPc is a high affinity laminin ligand and that this interaction mediates neuronal cell adhesion and neurite extension and maintenance. Moreover, PrPc-caveolin-1 dependent coupling seems to trigger the tyrosine kinase Fyn activation. These data provide the first evidence for PrPc involvement in signal transduction.

\author{
Key words \\ - PrPc \\ - Cellular function \\ - Transmissible spongiform \\ encephalopathies \\ - Laminin \\ - Signal transduction \\ - Copper
}

\section{Introduction}

The cellular prion protein was first identified in experiments conducted in an attempt to find the exogenous nucleic acid component of the infectious agent responsible for neurodegenerative diseases called transmissible spongiform encephalopathies (TSE). This agent was partially purified from the brain of affected animals. An insoluble protein of 33-35 kDa designated PrPsc (prion scrapie) which generates a $27-30-k D a$ form after protease treatment was identified as the major component of the agent. Amino acid 
sequencing of the amino-terminal region from the purified protein allowed the synthesis of an isocoding mixture of nucleotides that was subsequently used to identify prion cDNA clones. The amino-terminal peptide was also used to produce polyclonal antibodies. These reagents allowed the identification of a chromosomal gene and a host cellular protein, $\operatorname{PrPc}$, expressed in a variety of neuronal and nonneuronal tissues independently of the infection by scrapie or any other TSE agent (1).

The participation of $\mathrm{PrPc}$ is absolutely necessary for infection since animals in which the PrP gene has been ablated are totally resistant to the infection (2). PrPc and PrPsc have the same amino acid composition, although the $\alpha$-helix content of PrPc is about $40 \%$, with less than $10 \%$ ß-sheet conformation. In contrast, PrPsc shows about $50 \%$ of its structure as a $\beta$-sheet. Therefore, it was proposed that gain of infectivity is a consequence of conformational modification of PrPc by PrPsc (1).

$\mathrm{PrPc}$ protein is highly conserved among species; the similarity is about 85 to $97 \%$ among mammals (3) and the comparison between primates and humans showed amino acid identity ranging from 92.9 to $99.6 \%$ (4). PrPc has also been described in chickens (3) and turtles (5). The entire open reading frame of all known PrP genes is located in a single exon which codes for a protein of approximately 250 amino acids (3). A signal sequence of 22 amino acids is present at the amino-terminal (6) and a 23-amino acid signal sequence encoding for attachment to a glycosylphosphatidylinositol (GPI) anchors at the carboxy-terminal sequence (7).

The cellular prion protein has some characteristics that make it a very interesting molecule and its conservation among species strongly suggests its relevance in physiological processes. Moreover, the role of PrPc in TSE is viewed as gain of function due to accumulation of a new PrPc isoform, PrPsc. However, it is still possible that prion diseases could be mediated, at least in part, by loss of function $(8,9)$.

During the last few years several research groups have been working with different models aiming to understand the physiological function of PrPc. Since this protein is a cell surface molecule its role could be related to ligand uptake, cell adhesion and recognition or cell signaling (10). Herein we intend to present an overview of the possible functions of cellular prion protein.

\section{Generation of PrP-deleted animals}

The generation of animals in which the gene that codes for a protein of interest is deleted, is a very interesting approach to study the unknown function of this gene in cellular or animal physiology.

Charles Weismann's group generated the first PrPc gene (Prnp)-deleted mouse ( $\mathrm{PrP}^{-/-}$ Zrch) in 1992 by homologous recombination replacing the Prnp open reading frame with the neomycin phosphotransferase gene under control of the herpes simplex virus thymidine kinase promoter (11). They performed learning, immunologic and anatomical tests in order to determine if $\mathrm{PrPc}$ is essential in some of these processes. The structure of $\mathrm{PrP}^{-/-}$mouse brain was normal and no detectable effect on the level of lymphocyte surface MHC class I and II antigen markers was observed. Behavior analysis with these mice included three tests: swimming navigation to find a submerged platform, Y-maze discrimination and two-way avoidance with shock sensitivity. Normal and $\mathrm{PrP}^{-/-}$mice showed a poor but overall significant learning performance, which is typical for many mouse strains, but no significant differences between them were observed. These results were somehow disappointing since due to the high conservation of PrP among species and its brain expression, the research community was expecting important physiological deficiencies in those animals. However, at least two possibilities 
can be proposed: the resulting defect is so subtle that a selective disadvantage may emerge only after many generations, or the protein function is redundant (11).

One year later, the same group observed that these mice devoid of PrP are completely protected against scrapie disease, at least up to 13 months after inoculation. Moreover, even heterozygous Prnp $^{+/}$mice are partially protected, inasmuch as 9 of 10 scrapie-inoculated animals showed signs of scrapie only 253-322 days after inoculation but are still alive after 322 days, while all Prnp ${ }^{+/+}$ controls died within about 180 days (2). These observations definitely prove that the development of scrapie symptoms and pathology is strictly dependent on the presence of PrPc and also that the expression level of $\mathrm{PrPc}$ is inversely related to incubation time and disease progression.

A second Prnp ${ }^{-/-}$line was created (Npu) two years later by a different targeting strategy but again it was impossible to obtain information about the normal function of PrPc since the line showed normal development (12).

Later, the application of specific behavioral tests characterized some abnormalities imputable to the lack of PrPc in Zrch animals (the first generated $\mathrm{PrPc}^{-/-}$mice). Tobler and co-workers (13) described an alteration in circadian rhythms which correlated the circadian regulation function of $\mathrm{PrPc}$ with fatal familial insomnia (a hereditary disease associated with specific mutations of the Prnp gene). A weakened GABA-A receptor-mediated fast inhibition and impaired long-term potentiation (14) were also described and could be involved in the epileptiform activity seen in Creutzfeldt-Jakob disease. Prusiner's group (15) did not reproduce these results; however, we observed that these $\mathrm{Prnp}^{-/-}$mice have an increased sensitivity to seizures in four different epileptogenical models (16).

In an attempt to analyze different behavioral tasks of mice devoid of PrPc our group reported an increased locomotor activity in Prnp $^{-/-}$Zrch mice, but normal inhibitory avoidance learning and anxiety (17).

In 1996 Sakaguchi and co-workers (18) developed a third line of mice homozygous for a disrupted Prnp gene (Ngsk) and observed that these animals grew normally after birth, but at about 70 weeks of age all began to show progressive symptoms of ataxia. The brain of mice with neurological symptoms presented considerable atrophy of the cerebellum due to an extensive loss of Purkinje cells.

One year later another Prnp $\mathrm{Pr}^{-/}$mouse line was generated $(\mathrm{Rcm} 0)$ and also developed a late onset fatal ataxia (19). Thus, it was suggested that PrPc has a role in the longterm survival of Purkinje neurons. However, it was puzzling why Ngsk and Rcm0 mice developed a fatal ataxia while two other lines of $\mathrm{Prnp}^{-/}$mice did not exhibit any extensive CNS dysfunction.

In order to determine the role of PrPc in this phenotype, Moore's group (19) analyzed PrPc-related genes. Since most of these related genes are localized in clusters they sequenced large cosmid clones containing the Prnp gene and found a novel PrP-like gene named Doppel (German for double and also meaning downstream prion-like protein). The coding region for Doppel (Prnd) is located $16 \mathrm{~kb}$ downstream from the Prnp gene and two major transcripts of 1.7 and 2.7 $\mathrm{kb}$ as well as an unusual chimeric transcript, generated by intergenic splicing with Prnp, are produced. Interestingly, the chimeric transcript is up-regulated in the Ngsk and Rcm0 strains of $\mathrm{PrP}^{-/-}$mice that developed ataxia but not in Zrch or Npu strains with a normal phenotype. The authors suggest that Doppel overexpression may provoke neurodegeneration (19).

The construction of a mouse with a prion transgene rescues the ataxia and Purkinje cell degeneration phenotype in Ngsk Prnp ${ }^{-/-}$ mice (20), suggesting that PrPc and Doppel proteins might compete for a common re- 
ceptor protein (19). A few years ago our group described a receptor for prion protein (21) and we speculated that PrPc binding to this receptor should participate in PrPc internalization and signaling. The evaluation of PrPc, Doppel, a common ligand and their interaction with other proteins might allow the characterization of PrPc physiological function. This subject will be discussed later in this article.

\section{PrPc as a copper uptake protein}

There is increasing evidence supporting a functional role for PrPc in copper metabolism. Several studies have indicated that PrPc can bind copper. First, it was possible to isolate $\mathrm{PrPc}$ from hamster brain on a copper affinity column (22). Moreover, purified recombinant PrPc, as well as synthetic PrPcderived peptides, bind copper ions with micromolar affinity through four histidine-containing peptide repeats in the amino-terminal half of the protein (23-25). The repeated region contains five or six octapeptide tandem motifs of the general form $\mathrm{P}(\mathrm{H} / \mathrm{G})$ GGGWGQ and is highly conserved among mammalian PrPc, while chicken PrPc has a similar region of eight hexapeptide tandem repeats (3).

Copper may contribute to PrPc conformation since the highly flexible amino-terminus of recombinant $\mathrm{PrPc}$ is more structured in the presence of copper (26). Moreover, spectroscopic data have suggested a bridged arrangement of coordinating histidine imidazole nitrogens binding four $\mathrm{Cu}^{2+}$ per PrPc molecule. This proposed coordination accounts for the cooperative binding of copper by PrPc (25).

Copper is an essential metal, which plays a fundamental role in the biochemistry of all aerobic organisms and is also required for the catalytic activity of several enzymes of interest to neurobiology (27). Free or incorrectly bound $\mathrm{Cu}^{2+}$ can catalyze the generation of damaging radicals such as hydroxyl radicals (28). Specific mechanisms have evolved in an appropriate compartmentalization and trafficking of this metal, avoiding oxidative stress (27).

Several groups have investigated the physiological meaning of the association between PrPc and copper. Brown and coworkers (24) reported that the copper content of membrane-enriched brain extracts from $\mathrm{PrP}^{-/-}$mice is $10-15$-fold lower than in wild-type controls while no significant difference was observed for other metals. These results suggested that $\mathrm{PrPc}$ is a major copper-binding protein in brain membrane fractions and controls the activity of other membrane-associated copper-binding proteins. The same group, using cerebellar cell cultures from mice expressing different levels of PrPc, demonstrated that cells with high levels of PrPc have an increasing resistance to oxidative stress compared to $\mathrm{PrP}^{-/-}$cells $(29,30)$.

The ability of PrPc to bind copper may modulate the activity of the major cellular antioxidant enzyme $\mathrm{Cu} / \mathrm{Zn}$ superoxide dismutase (SOD-1) and consequently cellular resistance to oxidative stress. Western and Northern-blot analysis indicated that mice either lacking or overexpressing PrPc had levels of $\mathrm{Cu} / \mathrm{Zn}$ SOD protein and mRNA equivalent to those expressed in wild-type mice. However, increasing levels of PrPc expression were linked to increased levels of $\mathrm{Cu} / \mathrm{Zn}$ SOD activity $(29,30)$. SOD-1 activity from cultured cerebellar neurons was approximately $50 \%$ the normal level in $\mathrm{PrPc}$ null mice and was elevated by $20 \%$ in transgenic mice overexpressing PrPc. In addition, experiments using cells metabolically labeled with radioactive copper have shown that $\mathrm{Cu} /$ $\mathrm{Zn}$ SOD immunoprecipitated from cells overexpressing PrPc has higher levels of radioactivity when compared to PrPc-deficient cells (30). These observations suggest that PrPc may play some role in the delivery of copper to cuproenzymes such as SOD-1.

Morphological and biochemical investi- 
gations of different PrPc-transgenic mouse lines provide strong evidence for a predominantly synaptic location of $\operatorname{PrPc}(31)$. A reduction in copper concentration in synaptosomal preparations of $\mathrm{PrP}^{-/-}$mice has been observed $(24,31)$, indicating that PrPc is involved in synaptic copper homeostasis. In fact, electrophysiological studies have suggested that $\mathrm{PrPc}$ may regulate synaptic transmission by modulating copper content in the synaptic cleft $(24,31)$.

More recently, a study using mass spectrometry methodology (32) failed to find any difference in the amount of ionic copper in subcellular fractions from brains of mice with different PrPc expression levels. They also showed that the enzymatic activity of SOD-1 and cytochrome $c$ oxidase in brain extracts are similar for these groups, as also is the incorporation of copper into $\mathrm{Cu} / \mathrm{Zn}$ SOD. The results of Waggoner et al. (32) differ from others $(29,30)$ and suggest that $\mathrm{PrPc}$ is not the primary carrier responsible for copper entry into the brain and does not play a role in the specialized trafficking pathways involved in delivery of copper to SOD1 in this tissue.

The exact mechanism by which copper and $\mathrm{PrPc}$ are functionally related is not known at present. PrPc, on the cell surface, may function as a sink for chelation of extracellular copper ions or as a carrier protein for uptake and delivery of these cations to intracellular targets. Pauly and Harris (10) have reported that copper stimulates endocytosis of PrPc from the cell surface via clathrincoated pits. An attractive hypothesis to explain this observation is that PrPc may bind copper ions in the extracellular domain, deliver them to endocytic compartments and transfer these cations to other copper-carrier cytosolic proteins. The binding of copper could stimulate internalization of PrPc, altering its conformation and increasing its affinity for a putative endocytic transmembrane receptor (10).

Another possibility is that bound copper serves as an essential cofactor for an unknown enzymatic activity of PrPc. Indeed, it has recently been shown that recombinant chicken and mouse PrPc, as well as PrPc immunoprecipitated from mouse brain tissue, have SOD activity (33). These results suggest that PrPc has an enzymatic function dependent on copper incorporation and indicate that it could have a direct role in cellular resistance to oxidative stress.

Disturbances in copper homeostasis leading to CNS dysfunction are well documented in humans and animals. Some neurodegenerative diseases such as Menkes' syndrome, Wilson's disease, amyotrophic lateral sclerosis and Alzheimer's disease are linked to altered copper transport and homeostasis (27). The evidence that PrPc has a role in copper metabolism may be important in understanding the pathogenesis of prion diseases, since loss of this copper-related function (as a result of conversion to PrPsc) could help to explain some features of these disorders. Interestingly, early studies have revealed that cuprizone, a copper-chelating agent, induces neuropathological changes in mice similar to those found in prion diseases (27), suggesting a role for copper in these disorders.

\section{PrPc-binding proteins}

The identification of PrPc-binding proteins can provide insights into the function of PrPc and the molecular mechanisms involved in prion diseases. There are a number of structural features within PrPc that might allow it to interact with other proteins. Two potential sites for binding are an amphipathic helix near the middle of the molecule that in other proteins has been implicated in protein-protein interaction and the GPI anchor which may internalize and deliver signals (34). Many studies have been conducted in recent years to probe the interaction of $P r P$ with other molecules.

PrPc binds to a family of heparin-like 
compounds; this interaction can influence the intracellular fate of the prion protein and inhibits the conversion of PrPc to PrPsc (35). Heparin is a sulfated polyanion closely related to cellular glycosaminoglycans, which in turn are associated with PrPsc in amyloid plaques. Therefore, it was proposed that these molecules act by directly competing with the binding of PrPc or PrPsc to cellular glycosaminoglycans. A recent publication characterized the sulfated polyanion-binding properties of recombinant PrPc protein using surface plasmon resonance and showed that the PrPc affinity for polyanions is parallel to their anti-scrapie formation potency (36).

PrPc also associates with PrPsc and this interaction is more efficient when the two isoforms have the same sequence, explaining the "species barrier" for prion transmission. Telling and co-workers (37) suggested that PrPc binds a species-specific macromolecule designated protein $\mathrm{X}$ which might function as a molecular chaperone in the formation of PrPsc.

Using a yeast two-hybrid system, Edenhofer and co-workers (38) identified the heat shock protein 60 , a cellular chaperone, as a specific ligand for PrPc. The interaction site was mapped between amino acids 180 and 210 of the PrPc protein. In a recent report (39) BiP, another chaperone, was described to be associated with PrPc. This protein remains associated with PrPc mutants for an extended period of time. BiP normally interacts with misfolded or unassembled proteins, mediating their retrograde translocation for proteosomal degradation. The authors presumed that the impairment of the endosomal-lysosomal degradation leads to the accumulation of PrPsc.

Oesch and co-workers (34) also found that PrPc binds to glial fibrillary acidic protein (GFAP); however, studies with null mice for the GFAP gene revealed that this protein is not essential for TSE development (40).

In a study using a soluble tagged PrPc probe to screen an expression mouse brain cDNA library, six potential PrPc-binding proteins were identified (41). Four of them are coded by novel cDNAs, one is Nrf2 (NF-E2 related factor 2) and the last is apolipoprotein 1 (Aplp1), which plays a role in the pathogenesis of Alzheimer's disease. The authors suggested that Aplp1 and PrP may possibly interact on the surface of neuronal cells or in the vicinity of the plasma membrane, but the role of this interaction in the development of prion or Alzheimer's diseases remains to be clarified.

Bcl-2, an anti-apoptotic protein, was also reported to be associated with $\operatorname{PrPc}(42)$, with the binding site being located in the carboxy-terminal region of Bcl-2 which includes the transmembrane region. The authors suggested that Bcl-2 may act as a chaperone and induce conformational modifications in PrPc.

Another protein characterized as a $\mathrm{PrPc}$ ligand is the $37-\mathrm{kDa}$ laminin receptor precursor. This protein interacts with PrPc in vitro and in vivo and is overexpressed in organs that accumulate PrPsc (43), suggesting that it could be a receptor or co-receptor for the prion protein in mammalian cells.

Our group has described the interaction of $\mathrm{PrPc}$ with a $66-\mathrm{kDa}$ membrane protein both in vivo and in vitro, and antiserum against this ligand inhibits the toxicity of a prion-derived peptide towards neuronal cells in culture (21). The protein has been isolated on two-dimensional gels and its sequencing is underway. We will discuss the possible role of this protein in PrPc internalization and signaling in the last section of this article.

It is remarkable that, as previously described, PrPc binds to a large number of proteins; however, the physiological relevance of these interactions remains to be established.

We have recently characterized a specific high affinity binding between PrPc and laminin, an extracellular matrix protein. 
Moreover, we provide for the first time consistent data regarding the physiological role of a PrPc association with another protein $(44,45)$. These data will be discussed below.

\section{PrPc in neuronal survival and differentiation}

One of the proteins that associate with $\mathrm{PrPc}$ is laminin (44), a fact consistent with a possible PrPc function as a cell adhesion and recognition molecule. Laminin is an 800$\mathrm{kDa}$ heterotrimeric glycoprotein consisting of two short and one long polypeptide chains, predominantly found in basement membranes and known to play a pivotal role in cell proliferation, differentiation, migration and death (46). The cellular responses triggered by laminin are mediated by its interaction with cell membrane receptors. The best known receptors are integrins but non-integrin laminin receptors have also been described (47).

In the CNS, laminin has likewise been shown to mediate neuronal differentiation through its interaction with integrins. This interaction is characterized by neurite formation and extension, migration of neurons both in vitro and in vivo (48), neuronal as well as axonal regeneration (48), and prevention of neuronal death after kainic acid injections (49). In the last model, tissue-type plasminogen activator was found to act by converting plasminogen into plasmin, which subsequently degrades laminin. Even though the cell receptor involved was not identified, it was clear that detachment of neurons from a laminin substrate was the determinant event for neuronal death, characteristic of seizure models.

Our group has observed that $\mathrm{PrPc}^{-/-}$mice are more sensitive to seizures caused by three convulsant agents including kainic acid, suggesting that the absence of PrPc renders animals more susceptible to neuronal death due to laminin degradation (16). Moreover, a recent study (50) using cells from $\mathrm{PrPc}^{-/-}$ mice has shown that PrPc prevents serum deprivation-dependent apoptosis of neurons in culture and has suggested that PrPc might be similarly involved in neurite extension by these cells.

We have established the PrPc-laminin connection showing that $\mathrm{PrPc}$ is a specific, high affinity, saturable receptor for laminin and the binding site resides at the carboxyterminal decapeptide (RNIAEIIKDI) of the laminin $\gamma$-1 chain (44). Indeed, neurite extension observed in primary cultures of hippocampal neurons in the presence of intact laminin-1 was quite sensitive to anti-PrPc antibodies, whereas that elicited by the carboxy-terminal peptide was completely inhibited by such antibodies. Furthermore, the neuritogenesis elicited by intact laminin was substantially decreased and was not inhibited by anti-PrPc antibodies when cells were derived from $\mathrm{PrPc}^{-/-}$mice, whereas no neuritogenesis could be elicited from such neurons by the carboxy-terminal peptide alone.

Very recently, we described the importance of PrPc-laminin interaction for neuronal cell adhesion. Indeed, using chromophore-assisted laser microscopy we confirmed the importance of this interaction for neurite extension and also showed its involvement in neurite maintenance (45).

The mapping of the decapeptide RNIAEIIKDI as the PrPc-binding site in the laminin molecule is particularly important since the $\gamma-1$ chain is the most conserved in all laminin types (48). Therefore, these data support the notion that PrPc-laminin interaction could be important in a variety of tissues in which both PrPc and different laminin isoforms are expressed.

In fact, $\mathrm{PrPc}$ is present on the surface of lymphocytes and its expression is increased when cells are activated by concanavalin A. Blockage of PrPc with specific antibodies suppresses mitogen-induced activation (51), suggesting that PrPc could participate in lymphocyte activation. On the other hand, laminin inhibits the proliferation of lymphocytes 
stimulated by concanavalin A (52). Whether the PrPc-laminin interaction participates in this event remains to be evaluated.

\section{PrPc and signal transduction}

Due to its cell membrane localization, PrPc could participate in cell signaling pathways and some progress has been made in the identification and characterization of the signaling involving PrPsc molecules.

It was described (53) that bradykininstimulated calcium responses in scrapie-infected cells was reduced by 30 to $50 \%$ compared with uninfected cells. The authors suggested that prion infection compromises calcium channel function.

After Forloni and co-workers (54) reported that a 21-amino acid fragment of the prion protein (PrP 106-126) could be toxic when chronically exposed to primary rat hippocampal cultures, some results about signal transduction were generated. This peptide forms ion-permeable channels in planar lipid bilayer membranes and these channels are freely permeable to the most common physiological ions like $\mathrm{Ca}^{2+}$ and $\mathrm{Na}^{+}$(55). Moreover, it was also observed that the neurotoxic peptide increases intracellular free calcium concentration in cultured microglia from wild-type and $\mathrm{PrP}^{-/-}$mice (56). Later, this peptide was found to be involved in the activation of tyrosine kinases Lyn and Syk, initiating a signaling cascade that results in a transient release of intracellular calcium and activation of classical protein kinase $\mathrm{C}$ and the calcium-sensitive tyrosine kinase PYK2. Activation of MAP kinases ERK-1 and ERK2 follows as a subsequent downstream signaling event. An important point of the work of Combs et al. (57) is the demonstration that the signaling response elicited by neurotoxic peptide induces the production of neurotoxic products.

Nevertheless, important questions are still unanswered. How is the observed signal triggered? What is the nature of the signaling triggered by PrPc? What kind of molecules are involved in this event?

In an attempt to answer these questions our group has been working on the identification and characterization of a putative receptor for PrPc. We used the complementary hydropathy theory to predict a hypothetical peptide complementary to the human prion region from amino acid 114 to 126 (21) previously described to be neurotoxic in primary neuronal cultures (54) and responsible for PrPc internalization (58). Antiserum raised against the prion complementary peptide 114-126 recognized a $66-\mathrm{kDa}$ membrane protein that binds PrPc both in vitro and in vivo. Furthermore, the complementary peptide as well as antiserum against it inhibited the toxicity of a prion-derived peptide towards neuronal cells in culture.

Shmerling and co-workers (59) reported in 1998 that mice with PrP lacking residues 32-121 or 32-134 but not those deleted from 32 to 106 presented severe ataxia and neuronal death limited to the granular layer of the cerebellum as early as 1-3 months after birth. Interestingly, the deleted PrPc region involved in the disease maps on the predicted binding site for the putative receptor described by us (21), suggesting that PrPcreceptor interaction should be important for the normal function of PrPc. It is tempting to speculate that the PrPc region from amino acids 106-126 contains the binding site for the receptor association and signal transduction. Since $\mathrm{PrPc}^{-/-}$animals do not develop the disease a PrP-like molecule might bind to the receptor and transduce similar signals. Moreover, the truncated PrPc proteins do not act as dominant negative molecules for the receptor since the defect was completely abolished by introducing one copy of a wildtype PrP gene (59).

Very recent data have shown that $\mathrm{PrPc}$ triggers cell signaling increasing the phosphorylation levels of the tyrosine kinase Fyn, and caveolin-1 was characterized as the intermediate factor between PrPc on the outer 
membrane and the intracellular protein Fyn. However, the nature of the PrPc ligand responsible for the signal generation was not identified (60).

The two PrPc ligands characterized by us, the 66-kDa receptor (21) and laminin, seem to transduce signals through cAMP (Freitas AF, Martins VR and Brentani RR, unpublished results) and calcium (Lee KS, Prado MA, Brentani RR and Martins VR, unpublished results). Whether these two prion ligands can cooperate along the same pathway is still under investigation. Since laminin is located in the extracellular matrix and PrPc and PrPc 66-kDa receptor are located on the cell membrane, it is interesting to propose a connection between the extracellular milieu, the intracellular signaling, gene expression regulation and physiological events.

\section{References}

1. Prusiner SB (1998). Prions. Proceedings of the National Academy of Sciences, USA, 95: 13363-13383.

2. Büeler $H$, Aguzzi $A$, Sailer A, Greiner RA, Autenried $P$, Aguet $M \&$ Weissmann $C$ (1993). Mice devoid of PrP are resistant to scrapie. Cell, 73: 1339-1347.

3. Gabriel J -M, Oesch B, Kretzschmar $H$, Scott M \& Prusiner SB (1992). Molecular cloning of a candidate chicken prion protein. Proceedings of the National Academy of Sciences, USA, 89: 9097-9101.

4. Hermann MS, Da Costa M, Taylor L, Cohen FE \& Prusiner SB (1995). Prion protein gene variation among primates. J ournal of Molecular Biology, 245: 362374.

5. Simonic T, Duga S, Strumbo B, Asselta R, Ceciliani F \& Ronchi S (2000). cDNA cloning of turtle prion protein. FEBS Letters, 469: 33-38.

6. Turk E, Teplow DB, Hood LE \& Prusiner SB (1988). Purification and properties of the cellular and scrapie hamster prion proteins. European J ournal of Biochemistry, 176: 21-30.

7. Stahl N, Baldwin MA, Burlingame AL \& Prusiner SB (1990). Identification of glycoinositol phospholipid linked and truncated forms of the scrapie prion protein. Biochemistry, 29: 8879-8884.

8. Aguzzi A \& Weissmann C (1997). Prions research: the next frontiers. Nature, 389: 795-798.

9. Samaia HB, Mari JJ, Vallada HP, Moura RP, Simpson ATG \& Brentani RR (1997). A prion-linked psychiatric disorder. Nature, 390: 241.

10. Pauly P \& Harris DA (1998). Copper stimulates endocytosis of the prion protein. J ournal of Biological Chemistry, 273: 33107-33110.
11. Büeler $H$, Fischer $M$, Lang $Y$, Bluethmann H, Lipp HP, DeArmond SJ , Prusiner SB, Aguet M \& Weissmann C (1992). Normal development and behaviour of mice lacking the neuronal cell-surface PrP protein. Nature, 356: 577-582.

12. Manson J C, Clarke AR, Hooper ML, Aitchison L, McConnell I \& Hope J (1994). $129 /$ Ola mice carrying a null mutation in PrP that abolishes mRNA production are developmentally normal. Molecular Neurobiology, 8: 121-127.

13. Tobler I, Gaus SE, Deboer T, Achermann $P$, Fischer M, Rulicke T, Moser M, Oesch B, McBride PA \& Manson J C (1996). Altered circadian activity rhythms and sleep in mice devoid of prion protein. Nature, 380: 639-642.

14. Collinge J, Whittington MA, Sidle $K C$ Smith CJ, Palmer MS, Clarke AR \& J efferys J G (1994). Prion protein is necessary for normal synaptic function. Nature, 370: 295-297.

15. Lledo PM, Tremblay P, DeArmond SJ , Prusiner SB \& Nicoll RA (1996). Mice deficient for prion protein exhibit normal neuronal excitability and synaptic transmission in the hippocampus. Proceedings of the National Academy of Sciences, USA, 93: 2403-2407.

16. Walz R, Amaral OB, Rockenbach IC, Roesler R, Izquierdo I, Cavalheiro EA, Martins VR \& Brentani RR (1999). Increased sensitivity to seizures in mice lacking cellular prion protein. Epilepsia, 40: 16791682.

17. Roesler R, Walz R, Quevedo J , de-Paris F, Zanata SM, Graner E, Izquierdo I, Martins VR \& Brentani RR (1999). Normal inhibitory avoidance learning and anxiety, but increased locomotor activity in mice devoid of PrPc. Brain Research. Molecular Brain
Research, 71: 349-353.

18. Sakaguchi S, Katamine S, Nishida N, Moriuchi R, Shigematsu K, Sugimoto T, Nakatani A, Kataoka Y, Houtani T, Shirabe S, Okada H, Hasagawa S, Miyamoto T \& Noda T (1996). Loss of cerebellar Purkinje cells in aged mice homozygous for a disrupted PrP gene. Nature, 380: 528-531.

19. Moore RC, Lee IY, Silverman GL, Harrison PM, Strome $R$, Heinrich $C$, Karunaratne A, Pasternak SH, Chishti MA, Lian Y, Mastrangelo P, Wang K, Smit AF, Katamine $S$, Carlson GA, Cohen FE, Prusiner SB, Melton DW, Tremblay $P$, Hood LE \& Westaway D (1999). Ataxia in prion protein (PrP)-deficient mice is associated with upregulation of the novel PrPlike protein doppel. J ournal of Molecular Biology, 292: 797-817.

20. Nishida N, Tremblay $P$, Sugimoto $T$, Shigematsu K, Shirabe S, Petromilli $C$ Erpel SP, Nakaoke R, Atarashi R, Houtani T, Torchia M, Sakaguchi S, DeArmond SJ , Prusiner SB \& Katamine S (1999). A mouse prion protein transgene rescues mice deficient for the prion protein gene from Purkinje cell degeneration and demyelination. Laboratory Investigation, 79: 689-697.

21. Martins VR, Graner E, Garcia-Abreu J G, Souza SJ, Mercadante AF, Veiga SS, Moura Neto V \& Brentani RR (1997). Complementary hydropathy identifies a cellular prion receptor. Nature Medicine, 3: 1376-1382.

22. Pan K-M, Stahl N \& Prusiner SB (1992). Purification and properties of the cellular prion protein from Syrian hamster brain. Protein Science, 1: 1343-1352.

23. Hornshaw MP, McDermott J R, Candy J M \& Lakey J H (1995). Copper binding to the $\mathrm{N}$-terminal tandem repeat region of mam- 
malian and avian prion protein: structural studies using synthetic peptides. Biochemical and Biophysical Research Communications, 214: 993-999.

24. Brown DR, Qin K, Herms J W, Madlung A, Manson J , Strome R, Fraser PE, Kruck T, von Bohlen A, Schulz-Schaeffer W, Giese A, Westaway D \& Kretzschmar HA (1997). The cellular prion protein binds copper in vivo. Nature, 390: 684-687.

25. Viles J H, Cohen FE, Prusiner SB, Goodin DB, Wright PE \& Dyson HJ (1999). Copper binding to the prion protein: structural implications of four identical cooperative binding sites. Proceedings of the National Academy of Sciences, USA, 96: 20422047.

26. Miura T, Hori-IA \& Takeuchi H (1996). Metal-dependent $\alpha$-helix formation promoted by the glycine-rich octapeptide region of prion protein. FEBS Letters, 396: 248-252.

27. Waggoner DJ, Bartnikas TB \& Gitlin J D (1999). The role of copper in neurodegenerative disease. Neurobiology of Disease, 6: 221-230.

28. Atwood CS, Huang $X$, Moir RD, Tanzi RE $\&$ Bush AP (1999). Role of free radicals and metal ions in the pathogenesis of Alzheimer's disease. Metal Ions in Biological Systems, 36: 309-364.

29. Brown DR, Schulz-Schaeffer WJ , Schmidt B \& Kretzschmar HA (1997). Prion protein-deficient cells show altered response to oxidative stress due to decreased SOD1 activity. Experimental Neurology, 146: 104-112.

30. Brown DR \& Besinger A (1998). Prion expression and superoxide dismutase activity. Biochemical J ournal, 334: 423-429.

31. Herms J, Tings T, Gall S, Madlung A, Giese $A$, Siebert $H$, Schürmann $P$, Windl O, Brose N \& Kretzschmar H (1999). Evidence of presynaptic location and function of the prion protein. J ournal of Neuroscience, 19: 8866-8875.

32. Waggoner DJ, Drisaldi B, Bartnikas TB, Casareno RLB, Prohaska J R, Gitlin J D \& Harris DA (2000). Brain copper content and cuprozyme activity do not vary with prion protein expression level. J ournal of Biological Chemistry, 275: 7455-7458.

33. Brown DR, Wong B-S, Hafiz F, Clive C, Haswell SJ \& J ones IM (1999). Normal prion protein has an activity like that of superoxide dismutase. Biochemical J ournal, 344: 1-5.

34. Oesch B, Teplow DB, Stahl N, Serban D, Hood LE \& Prusiner SB (1990). Identification of cellular proteins binding to the scrapie prion protein. Biochemistry, 29:
5848-5855.

35. Gabison R, Meiner Z, Halimi M \& BemSasson SA (1993). Heparin-like molecules bind differentially to prion-proteins and change their intracellular metabolic fate. J ournal of Cellular Physiology, 157: 319325.

36. Brimacomb DB, Bennett AD, Wusteman FS, Gill AC, Dann J C \& Bostock CJ (1999). Characterization and polyanion-binding properties of purified prion protein. Biochemistry, 342: 605-613.

37. Telling CG, Scott $M$, Mastrianni J, Gabisom R, Torchia M, Cohen FE, DeArmond SJ \& Prusiner SB (1995). Prion propagation in mice expressing human and chimeric PrP transgenes implicates the interaction of cellular PrP with another protein. Cell, 83: 79-90.

38. Edenhofer $F$, Rieger $R$, Famulok $M$, Wendler W, Weiss S \& Winnacker E-L (1996). Prion protein PrPc interacts with molecular chaperones of the HSP 60 family. J ournal of Virology, 70: 4724-4728.

39. J in T, Gu Y, Zanusso G, Sy M, Kumar A, Cohen M, Gambetti P \& Singh N (2000). The chaperone protein BiP binds to a mutant prion protein and mediates its degradation by proteosome. J ournal of Biological Chemistry, 275: 38699-38704.

40. Gomi H, Yokoyama T, Fujimoto K, Ikeda T, Katoh A, Itoh T \& Itohara S (1995). Mice devoid of the glial fibrillary acidic protein develop normally and are susceptible to scrapie prions. Neuron, 14: 29-41.

41. Yehiely F, Bamborough P, Da Costa M, Perry BJ , Thinakaran G, Cohen FE, Carlson GA \& Prusiner SB (1997). Identification of candidate proteins binding to prion protein. Neurobiology of Disease, 3: 339-355.

42. Kurschner C \& Morgan JI (1996). Analysis of interaction sites in homo- and heteromeric complexes containing $\mathrm{Bcl}-2$ family members and the cellular prion protein. Brain Research. Molecular Brain Research, 37: 249-258.

43. Rieger R, Edenhofer $\mathrm{F}$, Lasmezas $\mathrm{Cl} \&$ Weiss S (1997). The human 37-kDa laminin receptor precursor interacts with the prion protein in eukaryotic cells. Nature Medicine, 3: 1383-1388.

44. Graner E, Mercadante AF, Zanata SM, Forlenza OV, Cabral ALB, Veiga SS, J uliano MA, Roesler R, Walz R, Minetti A, Izquierdo I, Martins VR \& Brentani RR (2000). Cellular prion protein binds laminin and mediates neuritogenesis. Brain Research. Molecular Brain Research, 76: 85-92.

45. Graner E, Mercadante AF, Zanata SM, Martins VR, J ay DG \& Brentani RR (2000).
Laminin-induced PC-12 cell neurite behavior following laser inactivation of cellular prion protein. FEBS Letters, 482: 257-260.

46. Timpl R \& Brown J (1994). The laminins. Matrix Biology, 14: 275-281.

47. Mercurio AM (1995). Laminin receptors: achieving specificity through cooperation. Trends in Cell Biology, 5: 419-423.

48. Luckenbill-Edds L (1997). LN and the mechanism of neuronal outgrowth. Brain Research Reviews, 23: 1-27.

49. Chen Z-L \& Strickland S (1997). Neuronal death in the hippocampus is promoted by plasmin-catalysed degradation of LN. Cell, 91: 917-925.

50. Kuwahara C, Takeuchi AM, Nishimura T, Haraguchi K, Kubosaki A, Matsumoto $Y$ Saeki K, Matsumoto $Y$, Yokoyama T, Itohara S \& Onodera T (1999). Prions prevent neuronal cell-line death. Nature, 400: 225-226.

51. Cashman NR, Loertsche R, Nalbantoglu J, Shaw I, Kascsak RJ, Bolton DC \& Bendheim PE (1990). Cellular isoform of the scrapie agent protein participates in lymphocyte activation. Cell, 61: 185-192.

52. Li YY \& Cheung HT (1992). Basement membrane and its components on lymphocyte adhesion, migration, and proliferation. J ournal of Immunology, 149: 3174-3181.

53. Kristensson $K$, Feuerstein $B$, Taraboulos A, Hyun WC, Prusiner SB \& DeArmond SJ (1993). Scrapie prions alter receptormediated calcium responses in cultured cells. Neurology, 43: 2335-2341.

54. Forloni G, Angeretti N, Chiesa R, Monzani $E$, Salmona M, Bugiani $O$ \& Tagliavini $F$ (1993). Neurotoxicity of a prion protein fragment. Nature, 362: 543-546.

55. Lin MC, Mirzabekov T \& Kagan BL (1997) Channel formation by a neurotoxic prion protein fragment. J ournal of Biological Chemistry, 272: 44-47.

56. Herms J W, Madlung A, Brown DR \& Kretzschmar HA (1997). Increase of intracellular free $\mathrm{Ca}^{2+}$ in microglia activated by prion protein fragment. Glia, 21: 253-257.

57. Combs CK, J ohnson DE, Cannady SB, Lehman TM \& Landreth GE (1999). Identification of microglia signal transduction pathways mediating a neurotoxic response to amyloidogenic fragments of $B$ amyloid and prion proteins. Journal of Neuroscience, 19: 928-939.

58. Shyng SL, Moulder KJ , Laesko A \& Harris DA (1995). The N-terminal domain of a glycolipid-anchored prion protein is essential for its endocytosis via clathrin-coated pits. J ournal of Biological Chemistry, 270: 14793-14800. 
59. Shmerling D, Hegyi I, Fischer M, Blättler T, Brandner S, Götz J , Rülicke T, Flechsig E, Cozzio A, von Mering C, Hangartner C, Aguzzi A \& Weissmann C (1998). Expres- sion of amino-terminal truncated PrP in the mouse leading to ataxia and specific cerebellar lesions. Cell, 93: 203-214.

60. Mouillet-Richard S, Ermonval M, Chebas- sier C, Laplanche J L, Lehmann S, Launay J M \& Kellermann O (2000). Signal transduction through prion protein. Science, 289: 1925-1928. 